\title{
Obeticholic acid ameliorates obesity and hepatic steatosis by activating brown fat
}

\author{
HANLIN ZHANG ${ }^{1,2}$, MENG DONG ${ }^{1,2}$ and XIAOMENG LIU ${ }^{3}$ \\ ${ }^{1}$ Key Laboratory of Animal Ecology and Conservation Biology, Institute of Zoology, Chinese Academy of Sciences, \\ Beijing 100101; ${ }^{2}$ Savaid Medical School, University of Chinese Academy of Sciences, Beijing 100049; \\ ${ }^{3}$ Institute of Neuroscience and Translational Medicine, Zhoukou Normal University, Zhoukou, Henan 466001, P.R. China
}

Received April 7, 2020; Accepted February 9, 2021

DOI: $10.3892 / \mathrm{etm} .2021 .10423$

\begin{abstract}
Obeticholic acid (OCA) is exemplified as a potent drug for treating primary biliary cirrhosis and nonalcoholic fatty liver disease by inhibiting bile acid synthesis. However, it remains unclear whether the effect of OCA is mediated by the function of brown adipose tissue (BAT). In the present study, brown adipogenesis differentiation in vitro and $\mathrm{db} / \mathrm{db}$ mouse model treated with OCA were used to assess the anti-obesity function by body weight tracking, $\mathrm{O}_{2}$ consumption, food intake, physical activity, glucose tolerance tests. In addition, uncoupling protein 1 (Ucp1) protein expression in brown adipose tissue was measured by western blotting, morphometry of brown adipose tissue was analyzed by hematoxylin and eosin staining. Hepatic steatosis was detected by Oil-Red O staining and serological analysis was performed to assess the effect of OCA on hyperlipidemia. OCA treatment enhanced brown adipocyte cell differentiation and upregulated the expression of the BAT-specific gene Ucp1) in C3H10T1/2 cells in vitro. Consistent with these findings, OCA increased whole-body energy metabolism and glucose homeostasis by enhancing BAT activity in vivo, and ultimately decreased body weight gain in $\mathrm{db} / \mathrm{db}$ mice. In addition, the results demonstrated that spontaneous hepatic steatosis in $\mathrm{db} / \mathrm{db}$ mice was ameliorated following OCA treatment. In summary, OCA functioned as a BAT activator to help ameliorate obesity and maintain glucose homeostasis in $\mathrm{db} / \mathrm{db}$ mice. The present results may provide a novel potential therapeutic approach to activate brown fat in patients with obesity and other metabolic disorders.
\end{abstract}

\section{Introduction}

Obesity is caused by excess fat accumulation, which exerts a negative effect on human health (1). Being overweight or

Correspondence to: Dr Xiaomeng Liu, Institute of Neuroscience and Translational Medicine, Zhoukou Normal University, 6 East Wenchang Street, Zhoukou, Henan 466001, P.R. China

E-mail: 1xmxm_99@126.com

Key words: obeticholic acid, brown adipose tissue, obesity, uncoupling protein 1 obese increases the risks of various complications, particularly cardiovascular diseases, diabetes and dyslipidemia (2). Therefore, methods for overcoming obesity have become a current topic of considerable interest. Increased energy expenditure might be an alternative option to diet, exercise and gastric bypass surgery (3). Based on accumulating evidence from recent studies, brown adipose tissue (BAT), a type of powerful energy-consuming fat, ameliorates diet-induced and genetic obesity $(4,5)$. Thus, an increase in BAT mass or activation may represent a novel approach to treating obesity and its complications.

Fatty liver, also known as hepatic steatosis or simple steatosis, is defined as abnormal triglyceride (TG) accumulation in hepatocytes. Nonalcoholic fatty liver disease (NAFLD) is the most common liver disorder occurring in developed countries (6). Generally, $>80 \%$ of obese people develop fatty liver (7), and certain patients may progress to fibrosis, cirrhosis, or even hepatocellular carcinoma (8). According to previous studies, adipokines from visceral adipose tissue (VAT) modulate fatty liver disease (9). For example, leptin reverses NAFLD in patients with severe lipodystrophy (10). Lower adiponectin levels and increased inflammation in patients with non-alcoholic steatohepatitis (NASH) suggest that adiponectin deficiency is an important risk factor for the development of steatohepatitis (11). Thus, adipose tissue is closely associated with the formation of fatty liver.

Body weight control via a combination of diet and exercise has been regarded as the main intervention to rescue hepatic fatty deposits; however, drug interventions, including peroxisome proliferator-activated receptor (PPAR) agonists, bile acid analogs, de novo lipogenesis inhibitors, antioxidants and immune modulators, are required for liver dysfunction in some patients with serious clinical cases $(8,12)$. Bile acids are common negative feedback medications used to decrease hepatic lipogenesis and steatosis (13). In addition, bile acid analogs and sequestrants may help modulate the bile acid concentration in the enterohepatic circulation and decrease serum lipid levels and hepatic fat accumulation (14,15).

Obeticholic acid (OCA), a bile acid analog, was originally developed to treat NAFLD as a natural ligand of the farnesoid $\mathrm{X}$ receptor (FXR). OCA indirectly inhibits cytochrome 7A1, the rate-limiting enzyme in bile acid biosynthesis, to reduce fat content (16). Although the activation of FXR target genes by OCA has consistently been demonstrated in fatty liver and 
OCA exerts a browning effect on white adipose tissue (17), it remains unclear whether OCA alters BAT function and/or improves hepatic fatty deposits through the endocrine regulation of brown fat.

The aim of the present study was to explore the effect of OCA on brown fat. C3H10T1/2 cells and $\mathrm{db} / \mathrm{db}$ mice were used to investigate the potential effect of OCA on BAT function. For the first time, the present study confirmed that OCA increased BAT activity in vitro and in vivo, increased energy expenditure, and ameliorated hepatic steatosis and obesity in $\mathrm{db} / \mathrm{db}$ mice. The current findings establish a previously unrecognized role of OCA in activating BAT and reducing obesity, which may provide insights into a potentially novel therapeutic approach to treat metabolic disorders.

\section{Materials and methods}

Animals. In total, 40 7-week-old male mice (weight, 35-38 g) of the genetic obesity model strain C57BLKS/J-Lepr-/Lepr-(db/db) and their wild-type littermates were purchased from the Model Animal Research Center of Nanjing University. For 8 weeks, all mice were housed with a 12/12-h light/dark cycle, fed ad libitum and provided free access to water. OCA (Shenzhen Botaier Scientific Co., Ltd.) was administered at doses of 7.5, 15 and $30 \mathrm{mg} / \mathrm{kg}$ per day, which were hereinafter referred to as the low, medium and high groups, respectively. OCA was prepared as homogeneous solution in 2\% (v/v) Tween-80 and orally administered once per day immediately after preparation. The wild-type littermates and $\mathrm{db} / \mathrm{db}$ control group were treated with $2 \%(\mathrm{v} / \mathrm{v})$ Tween-80 vehicle solution. The dose conversion between cell and animal experiment were referred to the peripheral blood volume in mice (accounting for $6 \%$ body weight) to clarify the possible effective concentrations. For example, if the experimental animal dose is $3 \mathrm{mg} / \mathrm{kg}$, then the blood concentration of this drug would be $50 \mu \mathrm{g} / \mathrm{ml}$, which is $10 \mathrm{X} \mathrm{LC} \mathrm{LC}_{50}$ for cells, making the $\mathrm{LC}_{50}$ in vitro $5 \mu \mathrm{g} / \mathrm{ml}$ and vice versa. Therefore, in the present study, $25 \mu \mathrm{g} / \mathrm{ml}$ OCA in vitro would be equal to $15 \mathrm{mg} / \mathrm{kg}$ animal dose in vivo.

All mice were euthanized using $\mathrm{CO}_{2}$ (with $2 \mathrm{l} / \mathrm{min}$ flow rate and in $20 \%$ of the chamber volume displacement per min) until complete cardiac arrest and sacrificed to collect organs. All animal studies were approved by the Institutional Animal Care and Use Committee of the Institute of Zoology (Beijing, China), and all experiments were performed under the oversight of the Office of Laboratory Animal Welfare (Chinese Academy of Sciences).

Cell culture. The mesenchymal stem cell line C3H10T1/2, which was purchased from National Experimental Cell Resource Sharing Platform (cat. no. 3111C0001CCC000665; https://cellresource.cn/fdetail.aspx?id=2778), was cultured in basal medium (DMEM supplemented with 10\% FBS; Gibco, Thermo Fisher Scientific, Inc.) until the cells were $100 \%$ confluent. Cells were incubated with basal medium supplemented with $1 \mu \mathrm{g} / \mathrm{ml}$ insulin, $1 \mathrm{nM} 3,3$,5-triiodo-L-thyronine (T3), $1 \mu \mathrm{M}$ dexamethasone, $0.5 \mathrm{mM}$ isobutylmethylxanthine and $0.125 \mathrm{mM}$ indomethacin for the first 2 days (all from Sigma-Aldrich; Merck KGaA). Then, the medium was replaced with differentiation medium (DMEM supplemented with $10 \%$ FBS, including $1 \mu \mathrm{g} / \mathrm{ml}$ insulin and $1 \mathrm{nM} \mathrm{T}$ ) for another
4 days until maturation, at which point the cells were subjected to phenotypic and functional evaluations. C3H10T1/2 was treated by $25 \mu \mathrm{g} / \mathrm{ml}$ OCA during the processing of brown adipogenesis differentiation. The constant culture condition is $37^{\circ} \mathrm{C}$ and $5 \% \mathrm{CO}_{2}$ for conventional culture or brown adipogenesis differentiation.

Reverse transcription-quantitative PCR (RT-qPCR). The differentiated C3H10T1/2 was washed with icy PBS (Gibco) for three times. After draining the last PBS, TRIzol (Invitrogen; Thermo Fisher Scientific, Inc.) was added into every culture well containing differentiated C3H10T1/2 cells and cell lysis was obtained. RNA concentration was then measured using a Nanodrop 2000 machine (Thermo Fisher Scientific, Inc.). A total of $2 \mu \mathrm{g}$ total RNA was reverse transcribed with M-MLV Reverse Transcriptase (cat. no. M1705; Promega Corporation). The reaction system contained $1.0 \mu \mathrm{g}$ Oligo (dT) primer (Takara Bio, Inc.) and $2 \mu \mathrm{g}$ RNA sample in a total volume up to $17.75 \mu \mathrm{l}$ for the annealing solution. This annealing solution was heated to $70^{\circ} \mathrm{C}$ for $5 \mathrm{~min}$ and cooled immediately on ice before the following components were added: $5 \mu \mathrm{l} \mathrm{M}-\mathrm{MLV}$ 5X Reaction Buffer, 10 mM dNTP (Takara Bio, Inc.), 10 mM $1.25 \mu$ l Recombinant RNasin ${ }^{\circledR}$ Ribonuclease Inhibitor 25 units (Promega Corporation) and M-MLV Reverse Transcriptase. This reaction underwent $42^{\circ} \mathrm{C}$ incubation for $1 \mathrm{~h}$ to finish the first chain synthesis reaction. qPCR was performed with a GoTaq ${ }^{\circledR}$ qPCR Master Mix (cat. no. A6001; Promega Corporation) using an ABI Prism VIIA7 real-time PCR cycler (Applied Biosystems; Thermo Fisher Scientific, Inc.). Thermal cycling conditions: Polymerase activation for 1 cycle: $95^{\circ} \mathrm{C}$ for $2 \mathrm{~min}$; followed by 40 cycles of $95^{\circ} \mathrm{C}$ for $15 \mathrm{sec}$ and $60^{\circ} \mathrm{C}$ for $1 \mathrm{~min}$. Cyclophilin A was used as an internal reference gene. Relative fold changes in mRNA expression were calculated using the formula $2^{-\Delta \Delta \mathrm{Cq}}(18)$. The primer sequences are listed in Table I.

Western blotting. The cells were washed three times with PBS and lysed in RIPA buffer [50 mM Tris- $\mathrm{HCl}$ with $150 \mathrm{mM}$ $\mathrm{NaCl}, 1 \% \mathrm{NP} 40,0.25 \%$ sodium deoxycholate and inhibitors cocktail mixture (Roche Diagnostics; cat. nos. 4906837001 and 4693124001)] following the manufacturer's protocols to make a working solution. Brown fat tissue was isolated and rapidly dipped in RIPA buffer and ground with TissueLyser (Qiagen $\mathrm{GmbH}$ ). After centrifugation at $13,000 \times \mathrm{g}$ and $4^{\circ} \mathrm{C}$, the supernatant of extracted fluid from cells and brown fat was carefully separated, and the total protein concentration was quantified using a bicinchoninic acid protein assay (Pierce; Thermo Fisher Scientific, Inc.). A total of $20 \mu \mathrm{g}$ protein from each sample was separated by $10 \%$ SDS/PAGE and transferred to PVDF membranes (EMD Millipore). Then the membranes were incubated with $5 \%$ fat-free milk blocking buffer for $1 \mathrm{~h}$ at room temperature, and blotted with primary antibodies overnight at $4^{\circ} \mathrm{C}$. After washing with TBST (including $0.1 \%$ Tween 20 ) for three times, the membranes were incubated with HRP-conjugated secondary antibodies for $1 \mathrm{~h}$ at room temperature. The imaging signals were detected with a SuperSignal West Pico chemiluminescent substrate (Pierce; Thermo Fisher Scientific, Inc.). Primary antibodies against Ucp1 (1:1,000; Abcam; cat no. ab10983), oxidative phosphorylation-related proteins [dilution 1:250; Abcam; cat. 
Table I. Sequences of primers used for reverse transcription-quantitative PCR.

\begin{tabular}{lll}
\hline Gene & \multicolumn{1}{c}{ Forward primer $\left(5^{\prime}-3^{\prime}\right)$} & \multicolumn{1}{c}{ Reverse primer $\left(5^{\prime}-3^{\prime}\right)$} \\
\hline PPAR $\gamma 2$ & TCGCTGATGCACTGCCTATG & GAGAGGTCCACAGAGCTGATT \\
Ucp 1 & GAGGTCGTGAAGGTCAGAATG & AAGCTTTCTGTGGTGGCTATAA \\
Elovl3 & ATGCAACCCTATGACTTCGAG & ACGATGAGCAACAGATAGACG \\
PRDM16 & CAGCACGGTGAAGCCATTC & GCGTGCATCCGCTTGTG \\
CyclophillinA & TCCAAAGACAGCAGAAAACTTTCG & TCTTCTTGCTGGTCTTGCCATTCC
\end{tabular}

PPAR $\gamma 2$, peroxisome proliferator-activated receptor $\gamma 2$; Ucp1, uncoupling protein 1; Elov13, ELOVL fatty acid elongase 3; PRDM16; PR/SET domain 16.
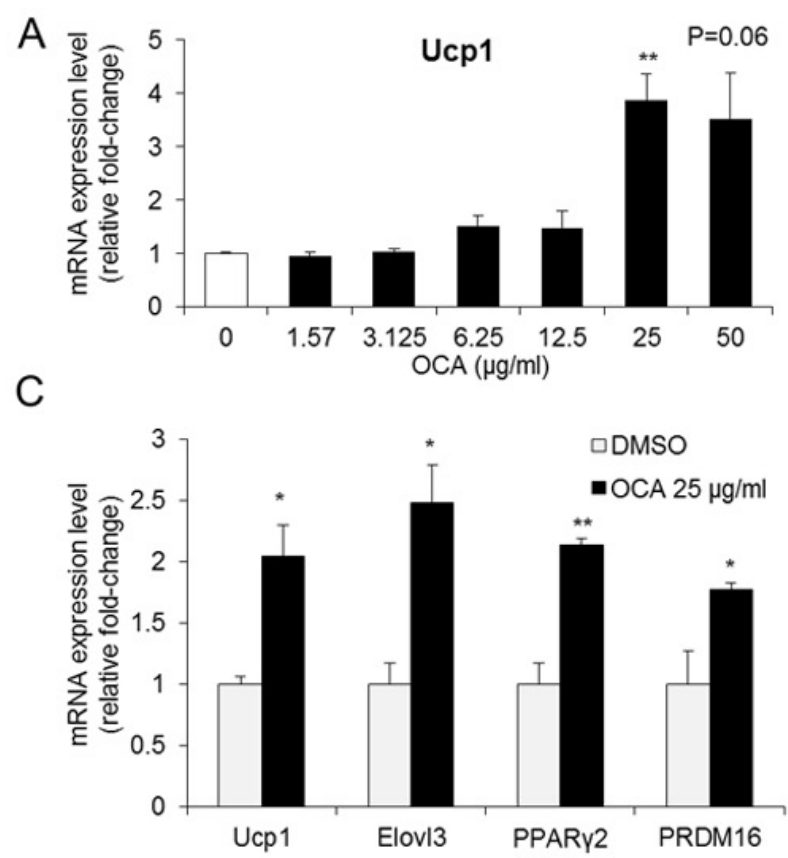

B

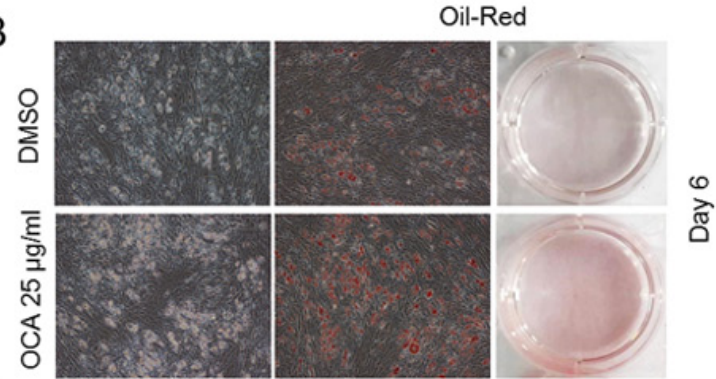

D

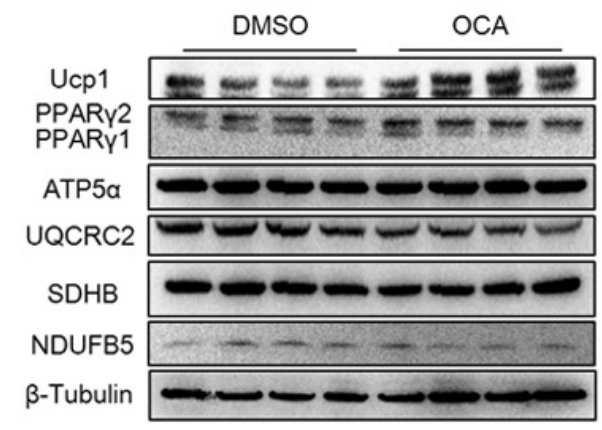

Figure 1. OCA enhances brown adipogenesis in C3H10T1/2 cells. (A) Effects of different concentrations of OCA on Ucp1 expression in undifferentiated C3H10T1/2 cells after treatment for $24 \mathrm{~h}(\mathrm{n}=5)$. ${ }^{* *} \mathrm{P}<0.05$ vs. 0 . (B) Representative photographs of Oil Red O staining in OCA-treated and control cells on day 6 of brown adipogenesis (Original magnification, x200). (C) The mRNA expression levels of brown adipocyte-specific genes and differentiation-related genes were detected in differentiated C3H10T1/2 cells from the control and OCA-treated groups $(\mathrm{n}=6)$. ${ }^{*} \mathrm{P}<0.05,{ }^{* *} \mathrm{P}<0.01$ compared with $\mathrm{DMSO}$ group. (D) The levels of fatty acid oxidation-related proteins were detected in differentiated C3H10T1/2 cells using western blotting ( $\mathrm{n}=4$ ). All data are presented as means \pm SEM. OCA, obeticholic acid; Ucp1, uncoupling protein 1; Elov13, ELOVL fatty acid elongase 3; PPAR $\gamma 2$, peroxisome proliferator-activated receptor $\gamma 2$; ATP5 $\alpha$, ATP synthase F1 subunit $\alpha$; UQCRC2, ubiquinol-cytochrome c reductase core protein 2; SDHB, succinate dehydrogenase complex iron sulfur subunit B; NDUFB5, NADH: Ubiquinone oxidoreductase subunit B5.

no. ab110413; a mixture of antibodies against ATP synthase F1 subunit $\alpha$ (ATP5 $\alpha$ ), ubiquinol-cytochrome c reductase core protein 2 (UQCRC2), mitochondrially encoded cytochrome c oxidase I (MTCO1), succinate dehydrogenase complex iron sulfur subunit B (SDHB) and NADH: Ubiquinone oxidoreductase subunit B5 (NDUFB5)], PPAR $\gamma$ (1:1,000; Cell Signaling Technology, Inc.; cat. no. 2443) and $\beta$-tubulin (dilution 1:1,000; Santa Cruz Biotechnology, Inc.; cat. no. sc-9104) were used. The secondary antibodies included the horseradish peroxidase (HRP)-conjugated goat anti-rabbit antibody (dilution 1:5,000; ZSGB-BIO; cat. no. ZDR-5306) and the HRP-conjugated goat anti-mouse antibody (ZSGB-BIO; cat. no. ZDR-5307). Densitometry analyses were performed using ImageJ software $1.48 \mathrm{v}$ (National Institutes of Health) from 3-4 samples per group.
Metabolic rate and physical activity. The metabolic rate was evaluated using a TSE Labmaster system (19). Each mouse was placed in a metabolic cage alone, and the volumes of $\mathrm{O}_{2}$ consumption and $\mathrm{CO}_{2}$ release were monitored in real-time over $24 \mathrm{~h}$. The physical activity of each mouse was measured with an optical beam technique (Opto-M3 animal activity meter; Columbus Instruments) and quantified by summing all motion points over $24 \mathrm{~h}(19)$.

Histology analysis. Brown adipose tissues were fixed with $4 \%$ paraformaldehyde at room temperature for $24 \mathrm{~h}$ and then embedded in paraffin. Sections with a thickness of $5 \mu \mathrm{m}$ were stained with hematoxylin and eosin (H\&E). De-paraffinization was performed using xylene. H\&E staining step, the sections were stained with hematoxylin for $10 \mathrm{~min}$ at room temperature 

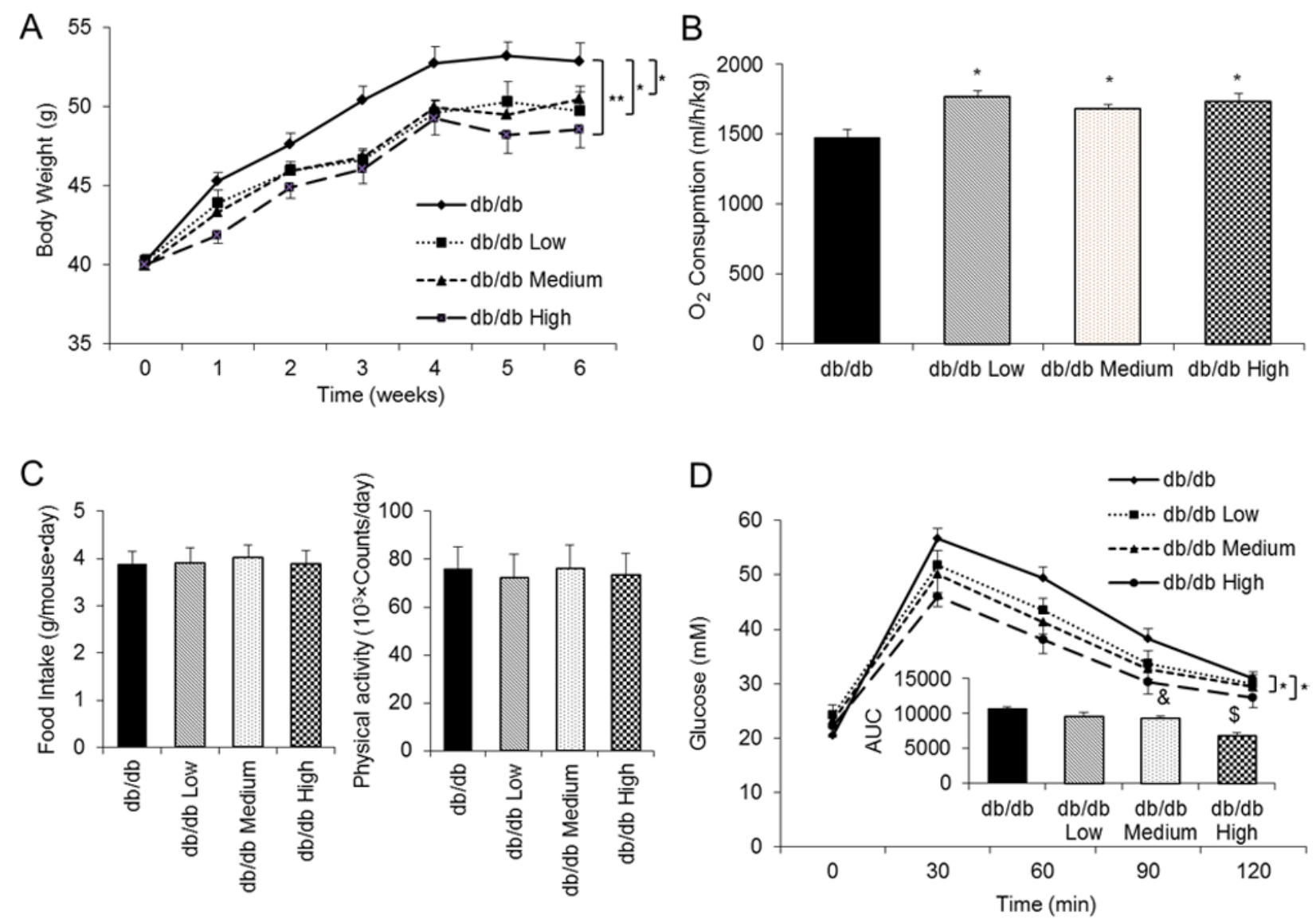

Figure 2. OCA inhibits body weight gain in $\mathrm{db} / \mathrm{db}$ mice and increases whole-body $\mathrm{O}_{2}$ consumption. (A) Body weight was recorded weekly for 6 consecutive weeks ( $\mathrm{n}=10$ mice per group). (B) The whole-body metabolic rate was determined by measuring $\mathrm{O}_{2}$ consumption in a single day after 4 week oral treatment ( $\mathrm{db} / \mathrm{db}$ control, $\mathrm{n}=6$; db/db Low, $\mathrm{n}=8$; db/db Medium, $\mathrm{n}=6$; and db/db High, $\mathrm{n}=8$ ). (C) Food intake and physical activity were recorded for a single day after 4 week oral treatment (db/db control, $n=7$; db/db Low, $n=9 ; \mathrm{db} / \mathrm{db}$ Medium, $\mathrm{n}=8$; and db/db High, $\mathrm{n}=9$ ). (D) The glucose tolerance test was conducted in the 5th week of treatment (db/db control, $\mathrm{n}=10$; db/db Low, $\mathrm{n}=10$; db/db Medium, $\mathrm{n}=9$; and db/db High, $\mathrm{n}=10$ ). All data are presented as means $\pm \mathrm{SEM}$. ${ }^{*} \mathrm{P}<0.05$ and ${ }^{* *} \mathrm{P}<0.01$ compared with the $\mathrm{db} / \mathrm{db}$ control group; ${ }^{\&} \mathrm{P}<0.05$ compared with the $\mathrm{db} / \mathrm{db}$ Low group; ${ }^{\$} \mathrm{P}<0.05 \mathrm{compared}$ with the db/db Medium group. OCA, obeticholic acid; AUC, area under the curve.

until the nucleus turned blue before being transferred into an eosin solution for 1-2 sec at room temperature and sealing with Neutral balsam. The stained sections would be kept in room temperature.

Fresh livers were fixed at room temperature for $24 \mathrm{~h}$ and dehydrated in a $30 \%(\mathrm{v} / \mathrm{v})$ sucrose solution overnight twice at room temperature. Properly sized tissues were embedded in OCT compound, frozen at $-80^{\circ} \mathrm{C}$ and prepared for cryosectioning (Sakura Finetek USA, Inc.), and the thickness of the sections was maintained at $12-15 \mu \mathrm{m}$. Oil Red O staining was performed using a previously described method (20). The stained sections would be kept in $4^{\circ} \mathrm{C}$. All photos are captured by light microscopy (ECLIPSE 80i; Nikon Corporation) and the magnification is $\mathrm{x} 200$.

Glucose tolerance test. Mice were fasted for $12 \mathrm{~h}$ (21:00-9:00) with free access to water. D-Glucose (Sigma-Aldrich; Merck KGaA) was intraperitoneally (i.p.) injected at a concentration of $0.75 \mathrm{~g} / \mathrm{kg}$ in saline, and blood glucose levels were measured with an Accu-Chek glucose monitor (Roche Diagnostics) at the indicated timepoints. The specific calculation method was described in a previous study (19).
ELISA. The following ELISA kits were used to detect blood lipid content in plasma samples according to the manufacturer's instructions: High-density lipoprotein cholesterol (HDL-C) assay kit (cat. no. E1017; Applygen Technologies Inc.), low-density lipoprotein cholesterol/very low-density lipoprotein cholesterol (LDL-C/VLDL-C) assay kit (cat. no. E1018; Applygen Technologies Inc.), serum triglyceride assay kit (cat. no. E1002; Applygen Technologies Inc.) and serum total cholesterol assay kit (cat. no. E1005; Applygen Technologies Inc.).

Statistical analysis. All data are presented as means \pm SEM. Data from multiple groups were analyzed using one-way ANOVA and Tukey's post hoc test, using GraphPad Prism version 6.04 (GraphPad Software, Inc.). Data from two groups were analyzed using the unpaired Student's t-test. $\mathrm{P}<0.05$ was considered to indicate a statistically significant difference.

\section{Results}

OCA enhances brown adipogenesis in C3H10T1/2 cells. $\mathrm{C} 3 \mathrm{H} 10 \mathrm{~T} 1 / 2$ cells were treated with OCA to investigate the potential effect of OCA on brown adipogenesis. OCA 


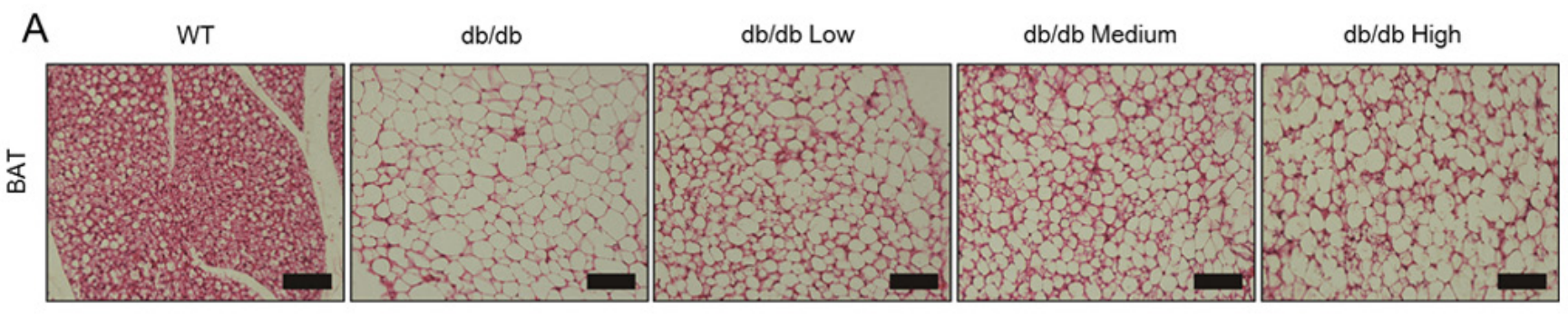

B

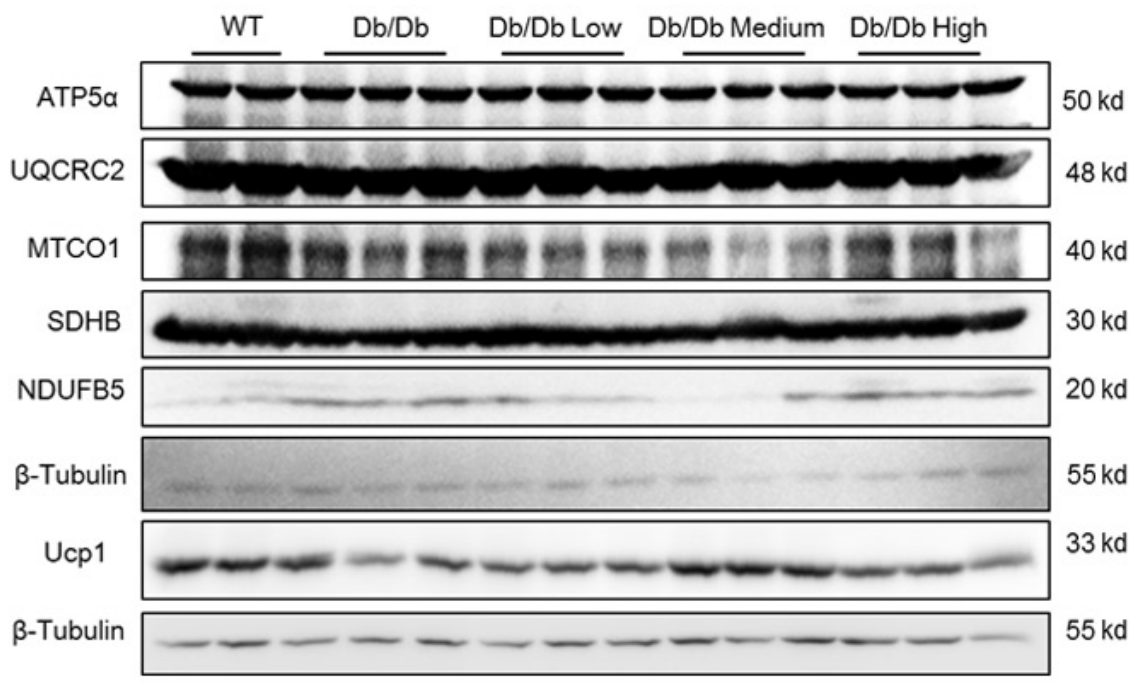

C

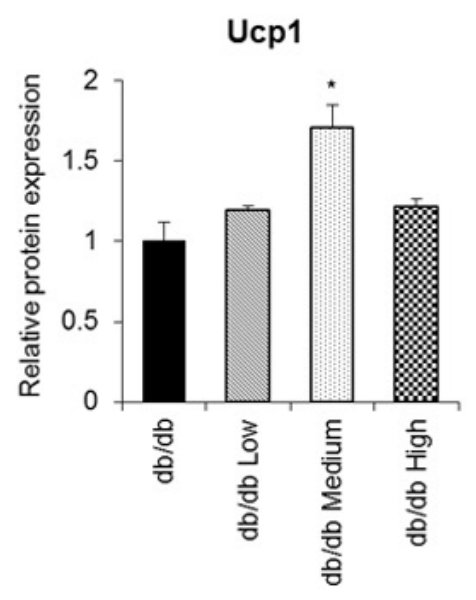

Figure 3. OCA induces Ucp1 expression in endogenous BAT. (A) Representative images of hematoxylin and eosin staining of endogenous BAT. Scale bar, $100 \mu \mathrm{m}$. (B) Representative blot images and (C) quantification of western blot analysis showing the levels of fatty acid oxidation-related proteins and Ucp1 in BAT from $\mathrm{db} / \mathrm{db}$ mice $(\mathrm{n}=3)$. $\beta$-Tubulin was used to normalize Ucp1 levels. All data are presented as means $\pm \mathrm{SEM}$. ${ }^{*} \mathrm{P}<0.05 \mathrm{compared}$ with the $\mathrm{db} / \mathrm{db}$ control group. OCA, obeticholic acid; Ucp1, uncoupling protein 1; BAT, brown adipose tissue; WT, wild-type; ATP5 $\alpha$, ATP synthase F1 subunit $\alpha$; UQCRC2, ubiquinol-cytochrome c reductase core protein 2; MTCO1, mitochondrially encoded cytochrome c oxidase I; SDHB, succinate dehydrogenase complex iron sulfur subunit B; NDUFB5, NADH: Ubiquinone oxidoreductase subunit B5.

significantly increased the mRNA expression levels of Ucp1, a BAT-specific gene, in C3H10T1/2 cells when administered at a concentration of $25 \mu \mathrm{g} / \mathrm{ml}$ for $24 \mathrm{~h}$ (Fig. 1A). Based on this result, the dose of $25 \mu \mathrm{g} / \mathrm{ml}$ was used in further experiments to evaluate the effect of OCA on brown adipogenesis. OCA treatment enhanced brown adipogenesis, as evidenced by the increase in Oil Red cell staining (Fig. 1B) and by the upregulation of the late adipogenic marker PPAR $\gamma 2$ (Fig. 1C). In addition, OCA treatment upregulated the mRNA expression levels of the BAT-specific genes Ucp1, ELOVL fatty acid elongase 3 and PRDM16 (Fig. 1C). These results were further confirmed by the increased protein expression levels of UCP1 and PPAR $\gamma 2$ following OCA treatment in C3H10T1/2 cells (Fig. 1D). Notably, OCA administration did not alter the levels of proteins involved in the oxidative phosphorylation pathway, such as ATP5 $\alpha$, UQCRC2, SDHB and NDUFB5 (Fig. 1D). Thus, OCA enhanced the brown adipocyte differentiation of C3H10T1/2 cells in vitro and specifically increased Ucp1 expression.

OCA delays body weight gain in db/db mice and increases whole-body $\mathrm{O}_{2}$ consumption. An increase in brown adipogenesis and Ucp1 expression is linked to energy metabolism $(21,22)$. C57BLKS/J-Lepr-/Lepr-(db/db) male mice were used as a model of obesity and diabetes to further investigate the function of OCA in vivo. According to the dose conversion from the in vitro experiment, mice were treated with three different doses $(7.5,15$ and $30 \mathrm{mg} / \mathrm{kg}$ per day, which were defined as low, medium and high groups, respectively) of OCA beginning at 7 weeks of age (Fig. 2A). OCA significantly inhibited body weight gain in the three OCA treatment groups compared with the control group (mean body weight at the end of experiment: Control group, $52.8 \mathrm{~g}$; low group, $49.7 \mathrm{~g}$; medium group, $50.4 \mathrm{~g}$; and high group, $48.5 \mathrm{~g}$; decrease in body weight compared with the control group, $5.8,4.5$ and $8.1 \%$, respectively; Fig. 2A). Of note, OCA treatment significantly increased energy metabolism, as evidenced by increased whole-body $\mathrm{O}_{2}$ consumption (Fig. 2B), without significantly altering food intake or physical activity (Fig. 2C). Furthermore, the results of the glucose tolerance test demonstrated that OCA treatment dramatically improved glucose tolerance (Fig. 2D). The area under the curve revealed a positive correlation between the improved glucose tolerance and the OCA dosage (Fig. 2D).

OCA activates endogenous BAT to ameliorate hepatic steatosis. Firstly, BAT morphology was investigated to obtain additional insights into the potential mechanism of OCA action. OCA treatment substantially reduced the size of BAT cells compared with the control treatment group and activated endogenous BAT (Fig. 3A). Accordingly, the expression levels of the UCP1 protein were significantly increased in medium group, but the levels of oxidative phosphorylation-related proteins were not altered (Fig. 3B and C). Considering 
A
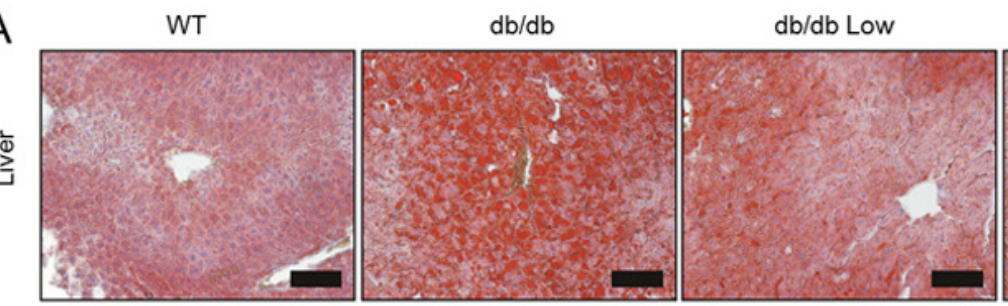

$\mathrm{db} / \mathrm{db}$ Medium

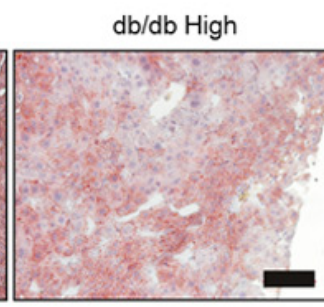

B

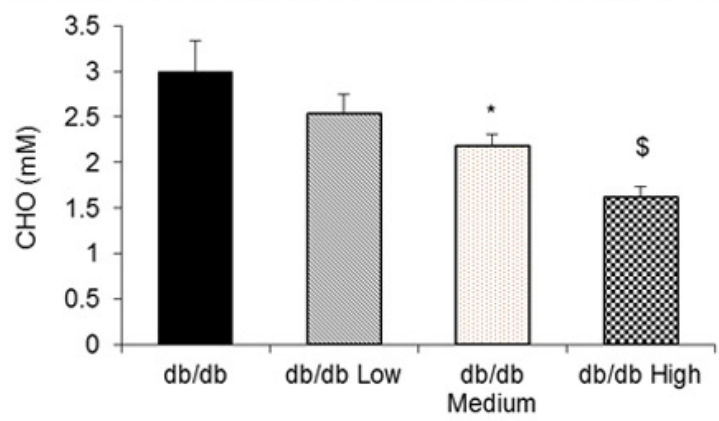

C
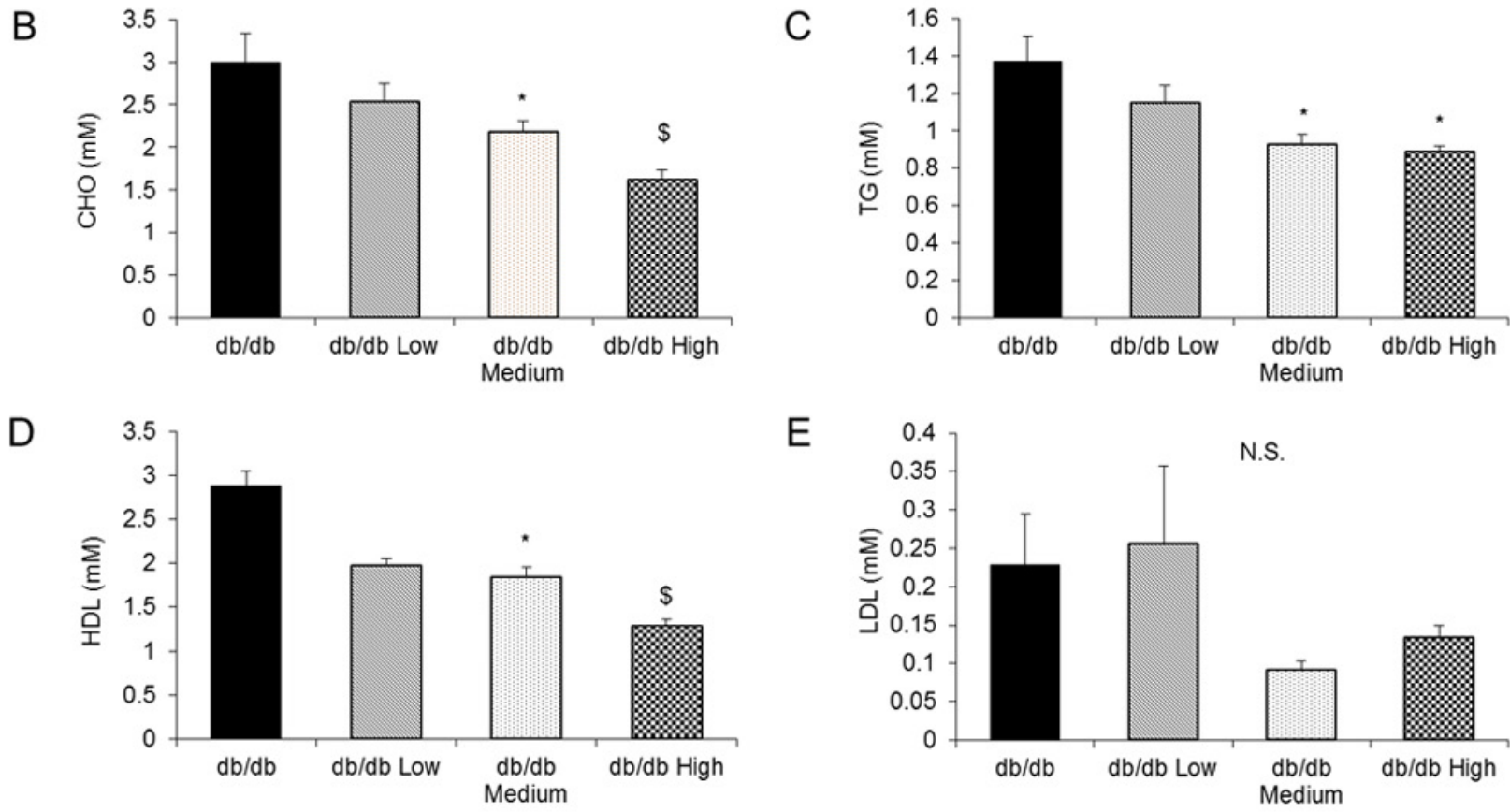

$\mathrm{E}$

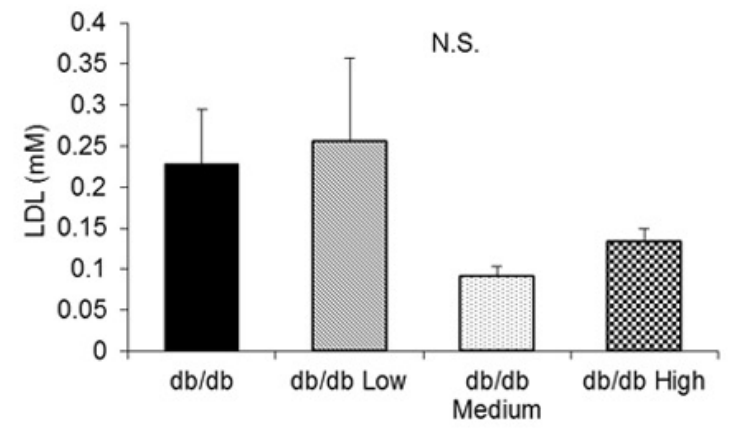

Figure 4. OCA reverses hepatic steatosis and hyperlipidemia. (A) Comparison of the liver morphology in each group using Oil Red O staining. Scale bar, $100 \mu \mathrm{m}$. (B) Serum CHO, (C) TG, (D) HDL-C and (E) LDL-C levels were detected using ELISA kits (db/db control, $\mathrm{n}=10$; db/db Low, $\mathrm{n}=10$; db/db Medium, $\mathrm{n}=9$; and $\mathrm{db} / \mathrm{db}$ High, $\mathrm{n}=10$ ). All data are presented as means \pm SEM. ${ }^{*} \mathrm{P}<0.05$ compared with the $\mathrm{db} / \mathrm{db}$ control group; ${ }^{\mathrm{S}} \mathrm{P}<0.05 \mathrm{compared}$ with the $\mathrm{db} / \mathrm{db}$ Medium group. OCA, obeticholic acid; CHO, cholesterol; TG, triglyceride; HDL-C, high-density lipoprotein cholesterol; LDL-C, low-density lipoprotein cholesterol; N.S., not significant.

the therapeutic potential of OCA as a treatment for hepatic steatosis, the present study investigated the effect of OCA on hepatic steatosis. OCA treatment significantly reversed hepatic steatosis, as evidenced by the Oil Red $\mathrm{O}$ staining of frozen liver sections (Fig. 4A). In addition, OCA administration significantly decreased serum total cholesterol, TG and HDL-C levels, but not the levels of LDL-C (Fig. 4B-E).

\section{Discussion}

The $\mathrm{db} / \mathrm{db}$ mouse strain is a leptin receptor-deficient mouse model that exhibits excess obesity, diabetes, polyuria, dyslipidemia and even liver damage during growth and development (23). These mice exhibit low levels of BAT activity and severe hepatic steatosis; therefore, the present study used $\mathrm{db} / \mathrm{db}$ mice as a model to evaluate the effects of OCA on obesity and fatty liver disease. The results demonstrated that OCA treatment increased brown adipogenesis, increased the expression of the BAT-specific gene Ucp1, enhanced whole-body energy consumption, improved glucose tolerance, and ultimately significantly reversed hepatic steatosis.

As an important heat production organ, BAT was initially shown to primarily maintain the body temperature of rodents and human infants in cold environments (24). However, based on accumulating evidence, activated BAT may serve critical roles in energy metabolism in rodents and adults (4). Unfortunately, several reports have detected only a small amount of BAT in adult humans. Therefore, affecting energy metabolism may be achieved by increasing the activity of BAT or by increasing beige fat cell formation (25). Although cold exposure activates endogenous BAT (26), it is not suitable for people with cardiovascular disease, in whom cold stimulation might increase the risk of death (27). Thus, other alternative methods of activation, such as orally available drugs, may be more suitable.

Bile acid participates in the intestinal absorption of fat and is recycled in the liver (28). Previous studies confirmed that bile acid, and its analogs, increase BAT mass and activity and ultimately decrease diet-induced obesity $(29,30)$. In addition, OCA modulates the adipose tissue phenotype by inducing the mRNA expression levels of fatty acid binding protein 4, CCAAT/enhancer-binding protein (C/EBP) $\alpha$ and PPAR $\gamma 2$ in 3T3-L1 cells and white adipocyte browning in atherogenic diet-fed wild-type mice $(17,31)$. In the present study, OCA treatment substantially increased PPAR $\gamma 2$ expression, but not $\mathrm{C} / \mathrm{EBP} \alpha$ and $\mathrm{C} / \mathrm{EBP} \beta$ expression (data not shown). Notably, for technical reasons, the expression levels of other BAT-related genes were not detected in the present study (data not shown), except for the upregulating PR/SET domain 16 gene (PRDM16). The expression of Zic family member 1 (Zic1), myelin protein 
zero like 2 (Eva1) or LIM homeobox protein 8 (Lhx8) could not be detected by RT-qPCR in the present study. Therefore, an analysis of the changes between control and treatment groups was not technically possible for these genes in the present study, although previous studies have shown expression of Zic1 in adipogenesis differentiation of C3H10T1/2 cells $(32,33)$. In the future, primary brown adipocyte cells will be used as a model for adipogenesis differentiation in vitro. As a typical example of drug repurposing, in the present study, OCA increased Ucp1 expression and activated endogenous BAT without altering fatty acid oxidation. Additionally, OCA increased whole-body energy consumption similar to bile acid in a high-fat diet mouse model (34). Evidence from another study similarly demonstrated that OCA treatment increased insulin sensitivity and improved glucose homeostasis in a phase II trial (35).

In the present study, the side effects of higher serum cholesterol and LDL-C concentrations but lower HDL-C observed in the OCA treatment group may be ascribed to the disrupted conversion of cholesterol to bile acids reported in clinical trials with humans $(36,37)$. Of note, serological indicators, such as a decrease in TG and cholesterol levels, in mouse and rat models are not identical to those in human samples $(38,39)$. This difference might be derived from the suppression of hepatic bile acid synthesis, alteration of the bile acid composition and subsequent inhibition of cholesterol absorption in the intestine (38). On the one hand, OCA may increase serum cholesterol concentrations by blocking bile acid biosynthesis from cholesterol and reducing bile acid deposition in humans (40). By contrast, the alteration of the bile acid composition and inhibition of cholesterol absorption in the intestine contribute to the serum cholesterol clearance in rodent models $(41,42)$. In the present study, the serum cholesterol levels were decreased, including total cholesterol, TG and HDL-C, but not LDL-C, while liver steatosis was improved. A previous study indicated that 'indirect factors' may exist in adipose tissue or other organs to reverse fatty liver disease while failing to activate FXR in subjects treated with OCA (17).

In previous studies, strategies designed to increase BAT activity were proposed as a promising approach to improve fatty liver and decrease blood lipid levels $(43,44)$. BAT activation improves corticosterone-induced hyperlipidemia by reducing de novo lipogenesis in the liver and TG secretion (45). In addition, higher BAT activity in individual adults has a negative correlation with NAFLD-related morbidity (46). Furthermore, brown adipocytes significantly alter hepatic lipid homeostasis and NAFLD in patients with diabetes (47). Given the spatial inaccessibility between BAT and the liver, BAT-derived secretory factors might have a critical role in organ crosstalk. Moreover, the transplantation of fetal brown adipocytes into type 1 diabetic mice decreases hepatic glucose production by inducing the production of insulin-like growth factor 1 through a direct and/or indirect effect on liver metabolism (48). Another batokine, neuregulin 4 (NRG4), selectively binds to hepatocytes and reduces de novo lipogenesis through an LXR and sterol regulatory element binding transcription factor 1-dependent mechanism (43). Similarly, the fat content in the human liver may be regulated by NRG4 through the same pathway.
Taken together, several BAT-derived endocrine factors may indirectly influence hepatic lipid metabolism. In the present study, it was indicated that OCA may reverse steatohepatitis via the BAT endocrine network. Future studies will aim to screen serum samples in detail to identify the direct factors and investigate their functions.

In summary, to the best of our knowledge, the present study is the first to demonstrate that OCA treatment ameliorated hepatic steatosis by increasing BAT activity. OCA stimulated brown adipogenesis and Ucpl expression in BAT in vitro. In addition, OCA treatment increased whole-body energy metabolism and glucose homeostasis by increasing BAT activity in vivo. In our next study, a mouse model of diet-induced obesity will be used to confirm the function of OCA. Furthermore, although OCA shows therapeutic potential in animal models, its benefits and safety profile must be confirmed in humans in clinical trials in the future. In summary, the present results describe a novel approach to activate BAT as a potential treatment for obesity and other metabolic disorders.

\section{Acknowledgements}

Not applicable.

\section{Funding}

The present study was supported by the National Key Research and Development Program of China (grant no. 2017YFC1001003) and grants from the National Natural Science Foundation of China (grant nos. 81770577, 81770834 and 81370951), the Strategic Priority Research Program from the Chinese Academy of Sciences (grant no. XDB13030000), the National Natural Science Foundation of China (grant no. Y21JA71234), the Open and Cooperation in Science and Technology Project of Henan Province (grant no. 182106000047) and the Innovative Talents in Universities of Henan Province (grant no. 19HASTIT015).

\section{Availability of data and materials}

The datasets used and/or analyzed during the current study are available from the corresponding author on reasonable request.

\section{Authors' contributions}

$\mathrm{HZ}$ and MD conceived the project and wrote the manuscript. $\mathrm{HZ}$ performed the experiments. MD and XL analyzed the results. All authors were involved in editing the paper and approved the final manuscript. MD and XL confirm the authenticity of all the raw data. All authors read and approved the final manuscript.

\section{Ethics approval and consent to participate}

All animal studies were approved by the Institutional Animal Care and Use Committee of the Institute of Zoology (Beijing, China), and all experiments were performed under the oversight of the Office of Laboratory Animal Welfare (Chinese Academy of Sciences). 


\section{Patient consent for publication}

Not applicable.

\section{Competing interests}

The authors declare that they have no competing interests.

\section{References}

1. Srivastava G and Apovian CM: Current pharmacotherapy for obesity. Nat Rev Endocrinol 14: 12-24, 2018.

2. Haslam DW and James WP: Obesity. Lancet 366: 1197-1209, 2005.

3. Cypess AM, Haft CR, Laughlin MR and $\mathrm{Hu} \mathrm{HCH}$ : Brown fat in humans: Consensus points and experimental guidelines. Cell Metab 20: 408-415, 2014

4. Liu X, Zheng Z, Zhu X, Meng M, Li L, Shen Y, Chi Q, Wang D, Zhang Z, Li C, et al: Brown adipose tissue transplantation improves whole-body energy metabolism. Cell Res 23: 851-854, 2013.

5. Liu X, Wang S, You Y, Meng M, Zheng Z, Dong M, Lin J, Zhao Q, Zhang C, Yuan X, et al: Brown adipose tissue transplantation reverses obesity in $\mathrm{Ob} / \mathrm{Ob}$ mice. Endocrinology 156 2461-2469, 2015.

6. Rinella ME: Nonalcoholic fatty liver disease: A systematic review. JAMA 313: 2263-2273, 2015.

7. Younossi Z, Anstee QM, Marietti M, Hardy T, Henry L, Eslam M, George J and Bugianesi E: Global burden of NAFLD and NASH: Trends, predictions, risk factors and prevention. Nat Rev Gastroenterol Hepatol 15: 11-20, 2018.

8. Chalasani N, Younossi Z, Lavine JE, Charlton M, Cusi K, Rinella M, Harrison SA, Brunt EM and Sanyal AJ: The diagnosis and management of nonalcoholic fatty liver disease: Practice guidance from the American association for the study of liver diseases. Hepatology 67: 328-357, 2018.

9. Antuna-Puente B, Feve B, Fellahi S and Bastard JP: Adipokines: The missing link between insulin resistance and obesity. Diabetes Metab 34: 2-11, 2008.

10. Chong AY, Lupsa BC, Cochran EK and Gorden P: Efficacy of leptin therapy in the different forms of human lipodystrophy. Diabetologia 53: 27-35, 2010

11. Polyzos SA, Toulis KA, Goulis DG, Zavos C and Kountouras J: Serum total adiponectin in nonalcoholic fatty liver disease: A systematic review and meta-analysis. Metabolism 60: 313-326, 2011.

12. Rotman Y and Sanyal AJ: Current and upcoming pharmacotherapy for non-alcoholic fatty liver disease. Gut 66: 180-190, 2017.

13. Watanabe M, Houten SM, Wang L, Moschetta A, Mangelsdorf DJ, Heyman RA, Moore DD and Auwerx J: Bile acids lower triglyceride levels via a pathway involving FXR, SHP, and SREBP-1c. $\mathrm{J}$ Clin Invest 113: 1408-1418, 2004.

14. Luo YH, Wang XX, Orlicky DJ and Levi M: Bile acid sequestrant prevents NAFLD and NASH in western diet fed mice independent of FXR. Hepatology 62: 280A-282A, 2015.

15. Yuan L and Bambha K: Bile acid receptors and nonalcoholic fatty liver disease. World J Hepatol 7: 2811-2818, 2015.

16. Massafra V, Milona A, Vos HR, Ramos RJJ, Gerrits J, Willemsen ECL, Ramos Pittol JM, Ijssennagger N, Houweling M, Prinsen HCMT, et al: Farnesoid X receptor activation promotes hepatic amino acid catabolism and ammonium clearance in mice. Gastroenterology 152: 1462-1476.e10, 2017.

17. Haczeyni F, Poekes L, Wang H, Mridha AR, Barn V Geoffrey Haigh W, Ioannou GN, Yeh MM, Leclercq IA, Teoh NC and Farrell GC: Obeticholic acid improves adipose morphometry and inflammation and reduces steatosis in dietary but not metabolic obesity in mice. Obesity (Silver Spring) 25: 155-165, 2017.

18. Livak KJ and Schmittgen TD: Analysis of relative gene expression data using real-time quantitative PCR and the 2(-Delta Delta $\mathrm{C}(\mathrm{T})$ ) method. Methods 25: 402-408, 2001

19. Yuan X, Wei G, You Y, Huang Y, Lee HJ, Dong M, Lin J, Hu T, Zhang $\mathrm{H}$, Zhang $\mathrm{C}$, et al: Rutin ameliorates obesity through brown fat activation. FASEB J 31: 333-345, 2017.

20. Zhang C, Wang J, Zhang H, Liu S, Lee HJ, Jin W and Cheng J: Hepatitis $\mathrm{C}$ virus core protein induces hepatic steatosis via Sirt1-dependent pathway. Liver Int 38: 803-812, 2018.
21. Trayhurn P, Thurlby PL and James WP: Thermogenic defect in pre-obese ob/ob mice. Nature 266: 60-62, 1977.

22. Kozak LP and Anunciado-Koza R: UCP1: Its involvement and utility in obesity. Int J Obes (Lond) 32 (Suppl 7): S32-S38, 2008.

23. Masuo K, Straznicky NE, Lambert GW, Katsuya T, Sugimoto K, Rakugi H, Socratous F, Hastings J, Lambert EA, Ogihara T and Esler MD: Leptin-receptor polymorphisms relate to obesity through blunted leptin-mediated sympathetic nerve activation in a Caucasian male population. Hypertens Res 31: 1093-1100, 2008

24. Cannon B and Nedergaard J: Brown adipose tissue: Function and physiological significance. Physiol Rev 84: 277-359, 2004.

25. Carey AL and Kingwell BA: Brown adipose tissue in humans: Therapeutic potential to combat obesity. Pharmacol Ther 140 26-33, 2013

26. Yoneshiro T, Aita S, Matsushita M, Kayahara T, Kameya T, Kawai Y, Iwanaga $\mathrm{T}$ and Saito M: Recruited brown adipose tissue as an antiobesity agent in humans. J Clin Invest 123: 3404-3408, 2013.

27. Tian L, Qiu H, Sun S and Lin H: Emergency cardiovascular hospitalization risk attributable to cold temperatures in Hong Kong. Circ Cardiovasc Qual Outcomes 9: 135-142, 2016.

28. Marin JJ, Macias RI, Briz O, Banales JM and Monte MJ: Bile acids in physiology, pathology and pharmacology. Curr Drug Metab 17: 4-29, 2016.

29. Broeders EP, Nascimento EB, Havekes B, Brans B, Roumans KH, Tailleux A, Schaart G, Kouach M, Charton J, Deprez B, et al: The bile acid chenodeoxycholic acid increases human brown adipose tissue activity. Cell Metab 22: 418-426, 2015.

30. Chen X, Yan L, Guo Z, Chen Y, Li M, Huang C, Chen Z and Meng X: Chenodeoxycholic acid attenuates high-fat diet-induced obesity and hyperglycemia via the $\mathrm{G}$ protein-coupled bile acid receptor 1 and proliferator-activated receptor $\gamma$ pathway. Exp Ther Med 14: 5305-5312, 2017.

31. Rizzo G, Disante M, Mencarelli A, Renga B, Gioiello A, Pellicciari R and Fiorucci S: The farnesoid X receptor promotes adipocyte differentiation and regulates adipose cell function in vivo. Mol Pharmacol 70: 1164-1173, 2006.

32. Rahman MS, Imran KM, Hossain M, Lee TJ and Kim YS: Biochanin A induces a brown-fat phenotype via improvement of mitochondrial biogenesis and activation of AMPK signaling in murine C3H10T1/2 mesenchymal stem cells. Phytother Res 35: 920-931, 2021.

33. Zhang HL, Huang YY, Lee HJ and Jin WZ: Zicl negatively regulates brown adipogenesis in $\mathrm{C} 3 \mathrm{H} 10 \mathrm{~T} 1 / 2$ cells. Sci Bull 60: 1033-1035, 2015.

34. Watanabe M, Houten SM, Mataki C, Christoffolete MA, Kim BW, Sato H, Messaddeq N, Harney JW, Ezaki O, Kodama T, et al: Bile acids induce energy expenditure by promoting intracellular thyroid hormone activation. Nature 439: 484-489, 2006.

35. Mudaliar S, Henry RR, Sanyal AJ, Morrow L, Marschall HU, Kipnes M, Adorini L, Sciacca CI, Clopton P, Castelloe E, et al: Efficacy and safety of the farnesoid X receptor agonist obeticholic acid in patients with type 2 diabetes and nonalcoholic fatty liver disease. Gastroenterology 145: 574-582.e1, 2013.

36. Papazyan R, Liu X, Liu J, Dong B, Plummer EM, Lewis RD II, Roth JD and Young MA: FXR activation by obeticholic acid or nonsteroidal agonists induces a human-like lipoprotein cholesterol change in mice with humanized chimeric liver. J Lipid Res 59: 982-993, 2018.

37. Pencek R, Marmon T, Roth JD, Liberman A, Hooshmand-Rad R and Young MA: Effects of obeticholic acid on lipoprotein metabolism in healthy volunteers. Diabetes Obes Metab 18: 936-940, 2016

38. Xu Y, Li F, Zalzala M, Xu J, Gonzalez FJ, Adorini L, Lee YK, Yin L and Zhang Y: Farnesoid X receptor activation increases reverse cholesterol transport by modulating bile acid composition and cholesterol absorption in mice. Hepatology 64: 1072-1085, 2016.

39. Cipriani S, Mencarelli A, Palladino G and Fiorucci S: FXR activation reverses insulin resistance and lipid abnormalities and protects against liver steatosis in Zucker (fa/fa) obese rats. J Lipid Res 51: 771-784, 2010.

40. Owsley E and Chiang JY: Guggulsterone antagonizes farnesoid $\mathrm{X}$ receptor induction of bile salt export pump but activates pregnane $\mathrm{X}$ receptor to inhibit cholesterol 7 alpha-hydroxylase gene. Biochem Biophys Res Commun 304: 191-195, 2003.

41. Lorbek G, Lewinska M and Rozman D: Cytochrome P450s in the synthesis of cholesterol and bile acids-from mouse models to human diseases. FEBS J 279: 1516-1533, 2012 
42. Modica S, Petruzzelli M, Bellafante E, Murzilli S, Salvatore L, Celli N, Di Tullio G, Palasciano G, Moustafa T, Halilbasic E, et al: Selective activation of nuclear bile acid receptor FXR in the intestine protects mice against cholestasis. Gastroenterology 142: 355-365.e1-e4, 2012

43. Wang GX, Zhao XY, Meng ZX, Kern M, Dietrich A, Chen Z, Cozacov Z, Zhou D, Okunade AL, Su X, et al: The brown fat-enriched secreted factor Nrg4 preserves metabolic homeostasis through attenuation of hepatic lipogenesis. Nat Med 20: 1436-1443, 2014.

44. Lee P, Linderman JD, Smith S, Brychta RJ, Wang J, Idelson C, Perron RM, Werner CD, Phan GQ, Kammula US, et al: Irisin and FGF21 are cold-induced endocrine activators of brown fat function in humans. Cell Metab 19: 302-309, 2014.

45. van den Beukel JC, Boon MR, Steenbergen J, Rensen PC, Meijer OC, Themmen AP and Grefhorst A: Cold exposure partially corrects disturbances in lipid metabolism in a male mouse model of glucocorticoid excess. Endocrinology 156 4115-4128, 2015.
46. Yilmaz Y, Ones T, Purnak T, Ozguven S, Kurt R, Atug O, Turoglu HT and Imeryuz N: Association between the presence of brown adipose tissue and non-alcoholic fatty liver disease in adult humans. Aliment Pharmacol Ther 34: 318-323, 2011.

47. Blondin DP, Labbé SM, Noll C, Kunach M, Phoenix S, Guérin B, Turcotte ÉE, Haman F, Richard D and Carpentier AC: Selective impairment of glucose but not fatty acid or oxidative metabolism in brown adipose tissue of subjects with type 2 diabetes. Diabetes 64: 2388-2397, 2015.

48. Gunawardana SC and Piston DW: Insulin-independent reversal of type 1 diabetes in nonobese diabetic mice with brown adipose tissue transplant. Am J Physiol Endocrinol Metab 308: E1043-E1055, 2015.

This work is licensed under a Creative Commons Attribution-NonCommercial-NoDerivatives 4.0 International (CC BY-NC-ND 4.0) License. 